(Berl. Ent. Z. 1887). I would recommend them, at the same time, to have my type specimen of $T$. trichoptera in the Mus. Comp. Zool. in Cambridge, Mass., carefully examined in order to ascertain whether my description is correct. I wrote and published the Western Diptera in a great hurry between my return from California in the autumn of 1876 and my final departure for Europe in the spring of 1877 , and I would in this case not trust my own statement without further verification.

Heidelberg, Germany, Feb. 12, I89.5.

\section{FAILURE TO EMERGE OF ACTIAS LUNA.}

In looking over a box of cocoons to-day, I came upon five, of $A$. luna, which felt suspiciously light. I cut them open, and in each $I$ found an undeveloped imago which had crawled out of the pupa-skin and had not been able to force its way out of the cocoon.

Each one lay with its head against the anal end of the empty pupa-skin, and the cocoon was filled with "fluff" made by the scales of the moth rubbed off in its struggle to get free.

Four days ago I received a large cocoon of $A$. luna, sent by mail, and one end of which was so wet that I expected the moth to emerge at any time. Instead, the wet spot dried, and two days later I cut open the cocoon, and found the moth with head and thorax out of the pupa-skin, and apparently dead. Taking the pupa out of the cocoon I began to cut away the skin, when the imago moved feebly. By the time I had removed all the pupa-skin the moth was sufficiently revived to cling to my finger, and was placed in a cage, where it hung for twelve hours without expanding the wings at all.

The next morning, however, the wings were fully spread, and the moth is now the largest + I have ever seen. The pupaskin was perfectly dry, and there has not been one drop of meconium discharged.

In the five cocoons first mentioned there was no meconium, and no evidence of the ends having been moistened.
This may be an experience common to entomologists, but it is entirely new to me.

Brookline, Mass.,

Caroline G. Soule.

June 2, 1894 .

\section{Entomological Notes.}

Dr. S. W. Williston of Lawrence, Kansas, has in press a work, entirely rewritten, on the classification and structure of North American Diptera. It will contain tables of all the North American genera, including those from Central America and the West Indies, together with descriptions of larvae, habits, anatomy, etc. It will appear next autumn. In its preparation he has had the assistance of Messrs. Aldrich, Townsend, Snow and Johnson, who have kindly prepared or revised the tables of the families with which they are best acquainted.

In a recent and excellently illustrated memoir (Musaeum Dzieduszyckianum, ivLemberg) on the insect fauna of the petroleum beds of Boroslow, Galicia, Lemnicki describes no less that seventy-six Coleoptera, of which nineteen are regarded as identical with living European insects, while the others find their nearest allies in boreal Europe, Asia and America. As only four species are identical with those found by Flach at Hösbach, Bavaria, in beds looked upon as Lower Pleistocene by Flach, and since the Hösbach Coleoptera as a whole show far less boreal affinities than those of Galicia, Lemnicki thinks the Hösbach fauna must be considered Middle Pleistocene and the Galician Lower Pleistocene. 

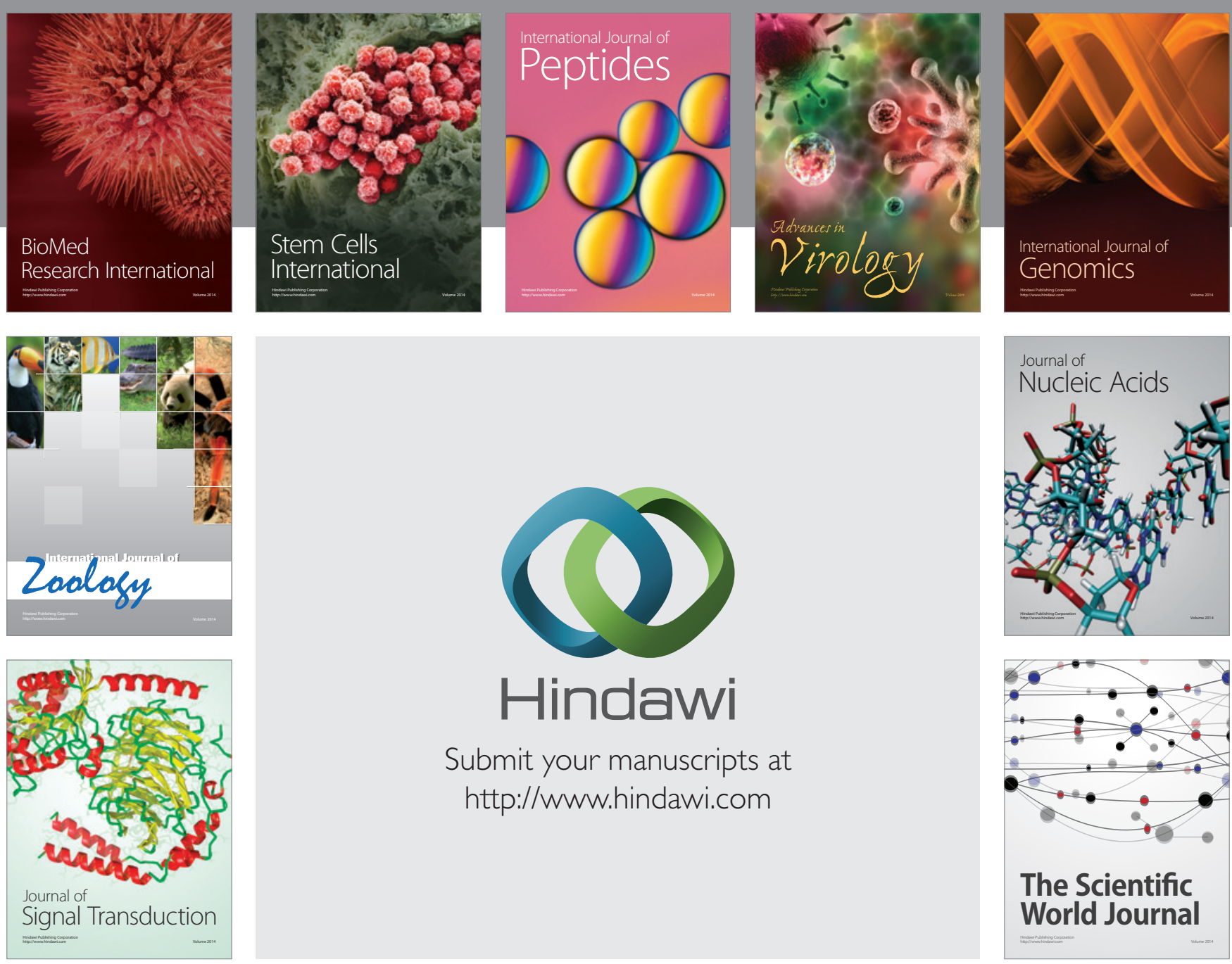

Submit your manuscripts at

http://www.hindawi.com
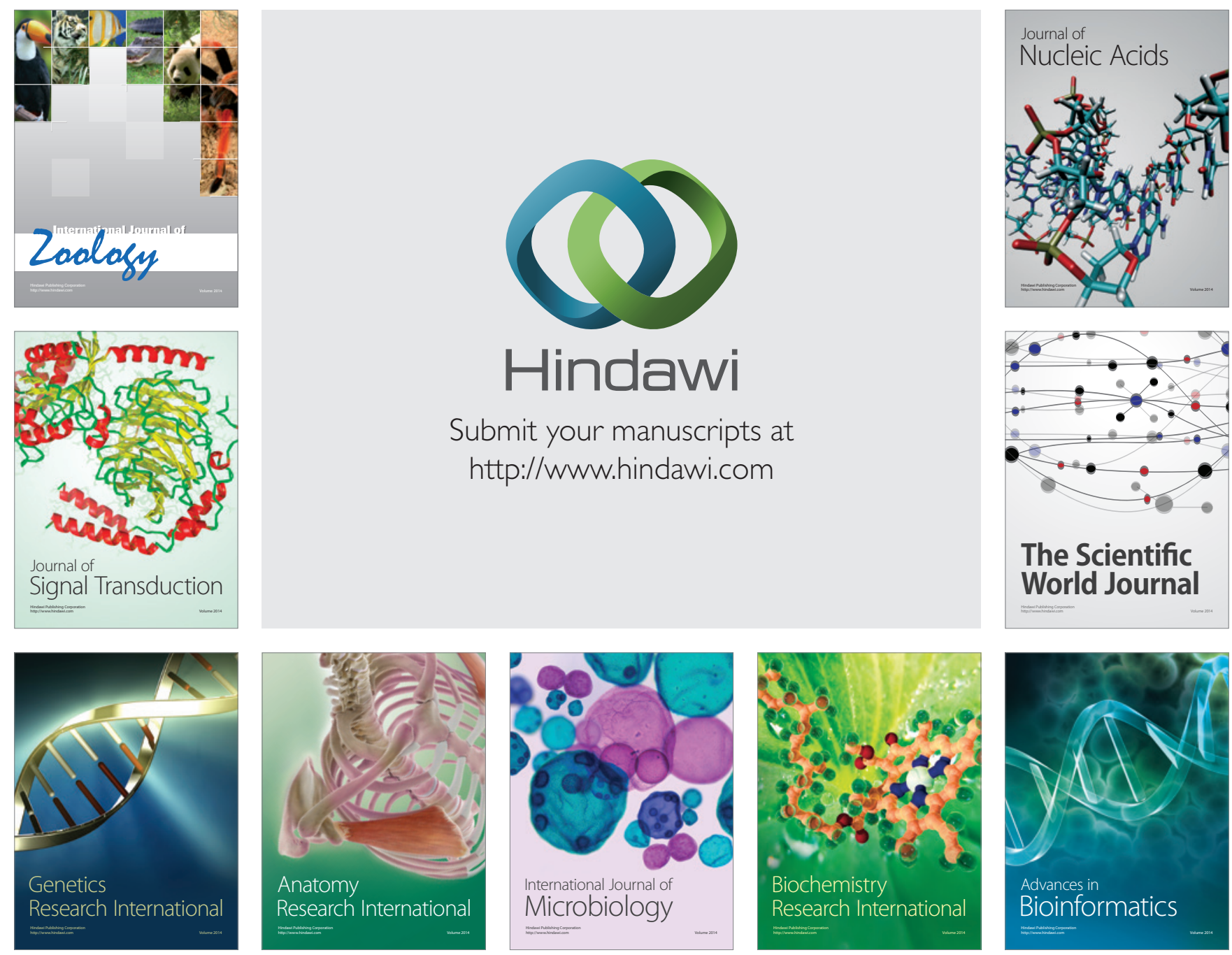

The Scientific World Journal
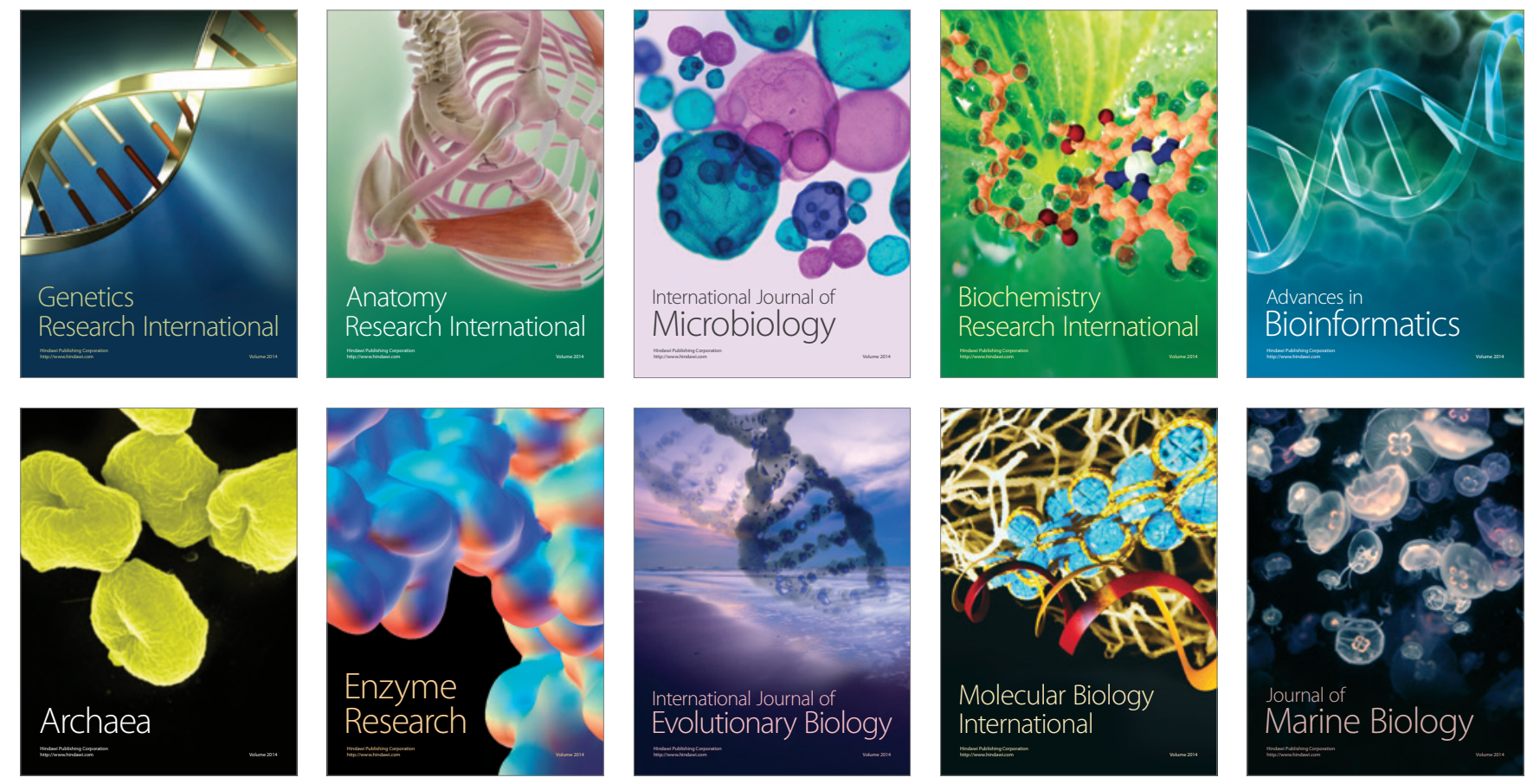